\title{
Formation of a metallic glass by thermal decomposition of $\mathrm{Fe}(\mathrm{CO}) 5$
}

\author{
Wonterghem, Jacques van; Mørup, Steen; Charles, Stuart W.; Wells, Stephen; Villadsen, J.
}

Published in:

Physical Review Letters

Link to article, DOI:

10.1103/PhysRevLett.55.410

Publication date:

1985

Document Version

Publisher's PDF, also known as Version of record

Link back to DTU Orbit

Citation (APA):

Wonterghem, J. V., Mørup, S., Charles, S. W., Wells, S., \& Villadsen, J. (1985). Formation of a metallic glass by thermal decomposition of Fe(CO)5. Physical Review Letters, 55(4), 410-413.

https://doi.org/10.1103/PhysRevLett.55.410

\section{General rights}

Copyright and moral rights for the publications made accessible in the public portal are retained by the authors and/or other copyright owners and it is a condition of accessing publications that users recognise and abide by the legal requirements associated with these rights.

- Users may download and print one copy of any publication from the public portal for the purpose of private study or research.

- You may not further distribute the material or use it for any profit-making activity or commercial gain

- You may freely distribute the URL identifying the publication in the public portal 


\title{
Formation of a Metallic Glass by Thermal Decomposition of $\mathrm{Fe}(\mathrm{Co})_{5}$
}

\author{
Jacques van Wonterghem and Steen Mørup \\ Laboratory of Applied Physics II, Technical University of Denmark, DK-2800 Lyngby, Denmark \\ and \\ Stuart W. Charles and Stephen Wells \\ Department of Physics, University of College of North Wales, Bangor, Gwynedd LL57 2UW, United Kingdom \\ and \\ Jørgen Villadsen \\ Haldor Topsøe Research Laboratories, DK-2800 Lyngby, Denmark \\ (Received 18 March 1985)
}

\begin{abstract}
Iron pentacarbonyl has been thermally decomposed in an organic liquid. Mössbauerspectroscopy and x-ray-diffraction studies show that the sample contains small particles of a metallic glass. Annealing of the particles at $523 \mathrm{~K}$ results in crystallization of the particles into a mixture of $\alpha-\mathrm{Fe}$ and $\chi-\mathrm{Fe}_{5} \mathrm{C}_{2}$. The mechanism of glass formation is discussed.
\end{abstract}

PACS numbers: $75.50 . \mathrm{Kj}, 75.50 . \mathrm{Mm}, 76.80 .+\mathrm{y}$

Metallic glasses are usually prepared by the liquidquench technique $^{1}$ or the vapor-deposition technique. ${ }^{2}$ Both methods are based on a rapid cooling at a rate which is sufficient to bypass nucleation and growth of crystalline phases.

Recently it was observed that an amorphous phase can be produced by the reaction of a crystalline intermetallic compound with hydrogen gas. ${ }^{3}$ The amorphous phase prepared by this method consisted of a hydride. The transition from the crystalline to the amorphous phase, a solid-state reaction, was explained in terms of a "chemical-frustration" effect. Later it was found that binary amorphous alloys can be formed by a solid-state diffusion reaction of pure polycrystalline metals under isothermal conditions. ${ }^{4}$ This was explained by the coincidence of two basic properties of the reaction: the fast diffusion behavior of one metal in the other and the existence of a negative heat of mixing in the amorphous alloy.

In this Letter, it is shown that a metallic glass can be formed by a pure chemical method, i.e., by the thermal decomposition of $\mathrm{Fe}(\mathrm{CO})_{5}$ in an organic liquid. The decomposition was expected to lead to the formation of $\alpha$-Fe particles. This method of carbonyl decomposition ${ }^{5,6}$ has been used to prepare small particles suitable for use in ferrofluids.

Ferrofluids are colloidal suspensions of small single-domain particles in a nonmagnetic carrier fluid. ${ }^{7}$ Colloidal stability is obtained in two ways. Firstly, the particles are coated with surfactant molecules, i.e., long-chain molecules which prevent close approach of the particles because of entropic repulsion. This results in a reduction in possible aggregation via short-range van der Waals forces. Secondly, the particles are made as small as possible to reduce long-range magnetic-dipole interactions between the particles.

In the present work, a ferrofluid was prepared by mixing a surfactant, Sarkosyl-O ( $n$-oleyoyl sarcosine), and iron pentacarbonyl in Decalin (decahydronaph- thalene). The mixture was refluxed and stirred for $5-6 \mathrm{~h}$ initially at $390 \mathrm{~K}$ rising to $460 \mathrm{~K}$ as the reaction proceeded. Initially a rapid evolution of $\mathrm{CO}$ occurred, when $\mathrm{Fe}(\mathrm{CO})_{5}$ decomposed to $\mathrm{Fe}_{2}(\mathrm{CO})_{9}$ and $\mathrm{Fe}_{3}(\mathrm{CO})_{12}$, setting up an equilibrium mixture of all three carbonyls. The $\mathrm{Fe}_{3}(\mathrm{CO})_{12}$ then decomposed, ultimately producing metallic particles of $8.5 \mathrm{~nm}$ median diameter and $\sigma=1.0 \mathrm{~nm}$. A constant flow of argon in the reaction vessel was maintained throughout the reaction to remove $\mathrm{CO}$ gas. ${ }^{6}$

Mössbauer spectra of the ferrofluid are shown in Fig. 1. Since the melting point of the fluid is about $220 \mathrm{~K}$, Mössbauer spectra were only obtained below this temperature in order to avoid line broadening due to diffusional motion of the particles. ${ }^{8}$

The spectrum obtained at $80 \mathrm{~K}$ [Fig. 1(b)] contains a magnetically split component with very broad lines. The average hyperfine field is $B_{\mathrm{hf}} \approx 26.0 \mathrm{~T}$, and the isomer shift is $\delta \approx 0.17 \mathrm{~mm} / \mathrm{s}$ relative to an absorber of $\alpha-\mathrm{Fe}$ at room temperature. The average quadrupole shift is negligible. The asymmetry in the spectrum is due to the presence of a $\mathrm{Fe}^{2+}$ doublet with line positions nearly coincident with those of lines 3 and 5 in the magnetically split component. The Mössbauer parameters of the six-line component are significantly different from those of $\alpha-\mathrm{Fe}$ at $80 \mathrm{~K}\left(B_{\mathrm{hf}}=33.9 \mathrm{~T}\right.$, $\delta=0.12 \mathrm{~mm} / \mathrm{s}$ ). The line broadening and the diminishing magnetic hyperfine splitting might be explained by the influence of collective magnetic excitations, ${ }^{9-11}$ i.e., fluctuations of the magnetization direction around an easy magnetization direction. However, the spectrum obtained at $80 \mathrm{~K}$ in an applied magnetic field, $B_{\text {ext }}=1.0 \mathrm{~T}$, perpendicular to the gamma-ray direction [Fig. 1(c)] exhibits similar linewidth and hyperfine splitting. Therefore the results cannot be explained by the presence of small $\alpha$-Fe particles affected by such relaxation effects, since these would be suppressed by the external magnetic field. ${ }^{10,11}$ Previous Mössbauer studies of $6-\mathrm{nm}$ particles of $\alpha$-Fe have shown that 


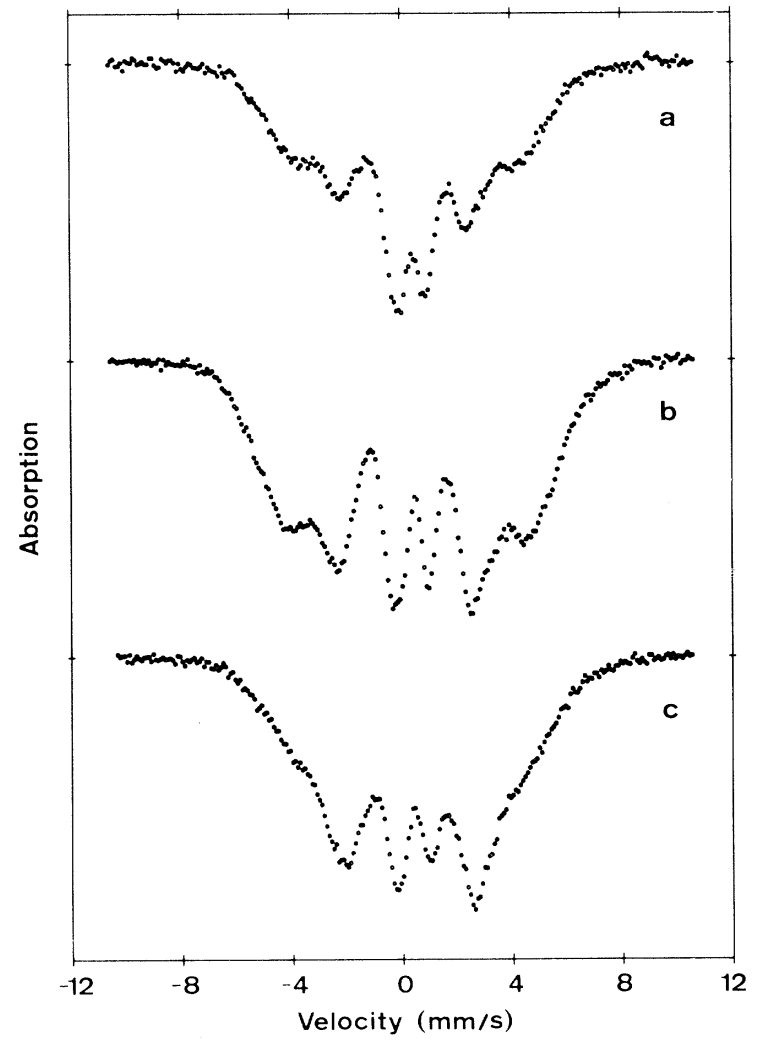

FIG. 1. Mössbauer spectra of the ferrofluid. (a) $166 \mathrm{~K}$, $B_{\text {ext }}=0$; (b) $80 \mathrm{~K}, B_{\text {ext }}=0$; and (c) $80 \mathrm{~K}, B_{\text {ext }}=1.0 \mathrm{~T}$.

under such conditions only the atoms in the first surface layer exhibit a magnetic hyperfine field that is significantly different from the bulk value. ${ }^{12,13}$ In the present study the only significant effect of the applied field is an increase in the relative intensities of lines 2 and 5, indicating that the particles are ferromagnetic and the magnetic moments of the particles are aligned parallel to the applied magnetic field.

At $166 \mathrm{~K}$ [Fig. 1(a)] a doublet appears in the spectrum indicating that some of the particles are superparamagnetic at this temperature. ${ }^{10}$ The finite value of the quadrupole splitting shows that the iron atoms are in noncubic environments. This result also shows that the particles do not consist of $\alpha$-Fe.

During the decomposition of the iron carbonyls carbon-monoxide molecules may be chemisorbed and dissociated at the surface of the particles and this might lead to formation of iron oxides and iron carbides. ${ }^{14}$ However, the Mössbauer parameters of the particles are significantly different from those of iron oxides and they are also different from those of crystalline iron carbides. ${ }^{15,16}$

The spectra are, however, very similar to those of metallic glasses. Specifically, the Mössbauer parameters are almost identical to those of an amorphous

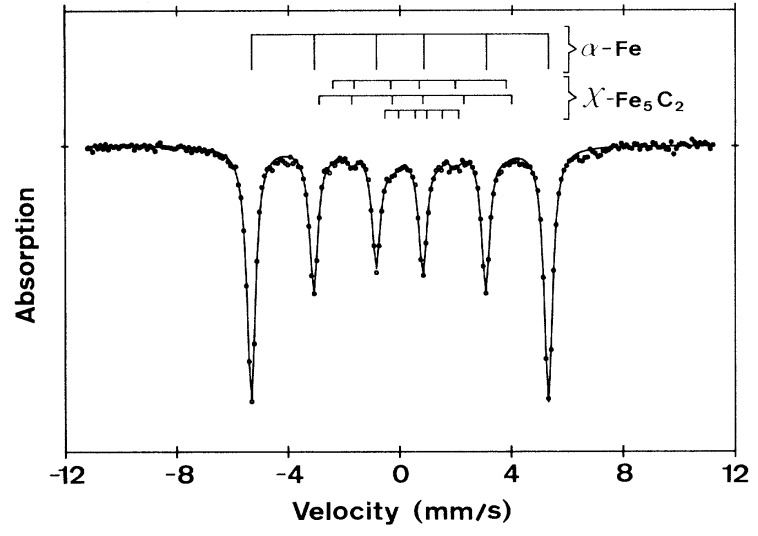

FIG. 2. Room-temperature Mössbauer spectrum of the particles after heating in hydrogen at $523 \mathrm{~K}$. The full line indicates a computer fit of the spectrum with a six-line component due to $\alpha-\mathrm{Fe}$, and three six-line components due to $\chi-\mathrm{Fe}_{5} \mathrm{C}_{2}$, as shown by the bar diagrams.

iron-carbon alloy with 5-10 at.\% carbon, prepared by sputtering. ${ }^{17}$ This type of metallic glass crystallizes into a mixture of $\alpha-\mathrm{Fe}$ and iron carbides at $523 \mathrm{~K} .{ }^{17}$ Therefore we have studied the sample after evaporation of the carrier liquid and heating at temperatures above $523 \mathrm{~K}$. The spectrum obtained after heating in argon at $573 \mathrm{~K}$ showed that the six-line component, which is predominant in Fig. 1(b), had disappeared, and a new six-line component, due to $\alpha-\mathrm{Fe}$, had appeared. However, part of the iron was oxidized during the annealing and this makes a detailed analysis of the crystallization difficult.

Therefore, another sample of the ferrofluid was dried and heated at $523 \mathrm{~K}$ in an in situ cell of Pyrex glass $^{18}$ in a flow of hydrogen. Figure 2 shows the room-temperature spectrum obtained after this treatment. The predominant component was unambiguously identified as the spectrum of $\alpha$-Fe. The remaining weak absorption lines indicate the presence of other magnetic phases with smaller magnetic hyperfine fields. The best computer fit (which is shown in Fig. 2) was obtained by including three additional six-line components of low intensity. The parameters of these components are in accordance with published values for $\chi-\mathrm{Fe}_{5} \mathrm{C}_{2}{ }^{15,16}$ The $\chi$-carbide component constitutes about $8 \%$ of the spectral area corresponding to about 11 at. $\%$ carbon in the particles.

Thus the Mössbauer studies show that the decomposition of $\mathrm{Fe}(\mathrm{CO})_{5}$ in the fluid results in the formation of metallic glass particles which crystallize into $\alpha$-Fe and iron carbide upon heating. The metallic glass prepared in the present work seems to be very similar to the amorphous iron-carbon alloy prepared by sputtering.

The $\alpha$-Fe component in Fig. 2 exhibits area ratios of the six lines which are different from those expected 
for polycrystalline samples with random orientation of the magnetic domains, i.e., 3:2:1:1:2:3. The reduced intensity of lines 2 and 5 shows that the magnetization is preferentially parallel to the $\gamma$-ray direction during the recording of the Mössbauer spectrum. This effect can be explained by the fact that the sample is exposed to a magnetic field produced by the heating coil during the recrystallization. The annealing then results in a macroscopic magnetization which is maintained after the heating current is switched off.

Further evidence for the formation of an amorphous alloy was obtained from $x$-ray-diffraction (XRD) studies. Figure 3(b) shows an XRD spectrum of the ferrofluid. The absence of diffraction lines in this spectrum indicates that the particles are indeed amorphous. However, since the particles are suspended in a liquid the result might also be explained by scattering of the $x$ rays by the liquid which could prevent observation of diffraction lines from crystalline particles. Therefore, an XRD spectrum of another ferrofluid, containing 9$\mathrm{nm}$ magnetite particles, was obtained under identical conditions. This spectrum, which is shown in Fig. 3 (a), contains very distinct diffraction lines. Thus the absence of diffraction lines in Fig. 3(b) is not due to scattering of the $\mathrm{x}$ rays by the liquid, but must be explained by the absence of crystalline phases in the ferrofluid prepared by carbonyl decomposition.

It is interesting to compare the mechanism of glass formation during carbonyl decomposition with the mechanisms involved during metallic glass formation by other techniques.

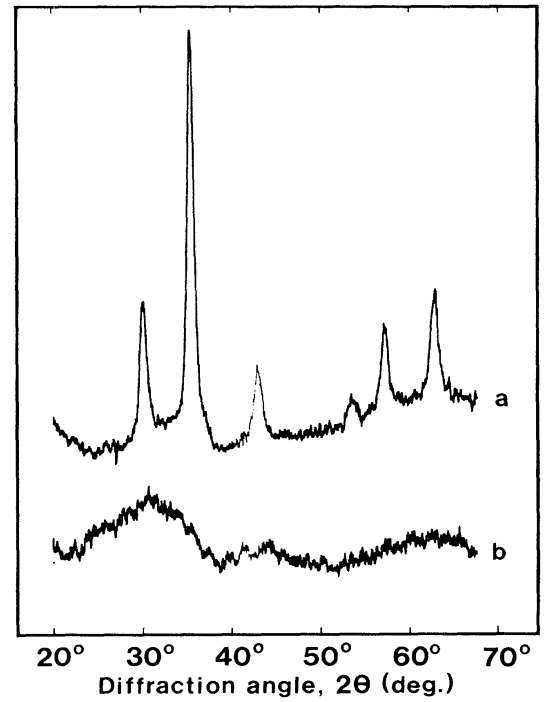

FIG. 3. X-ray diffractographs of (spectrum $a$ ) a ferrofluid with 9-nm magnetite particles, and (spectrum $b$ ) the ferrofluid prepared by carbonyl decomposition. The samples were run under identical conditions with use of $\mathrm{Cu} K \alpha$ radiation.
In order to form a glassy phase by liquid quenching the material must cool rapidly from the liquid state. The rates of nucleation and crystal growth, which are related to the diffusion rate, are significant in a temperature interval between the melting temperature, $T_{m}$, and the glass-transition temperature, $T_{g}$. Below $T_{g}$ the rate of crystallization is negligible. Typically, quenching rates $>10^{5} \mathrm{~K} \mathrm{~s}^{-1}$ are used in the temperature interval between $T_{m}$ and $T_{g}$. In this way the atoms are prevented from diffusing a sufficient distance to enable formation of nuclei. ${ }^{19-22}$

Preparation of amorphous alloys by vapor deposition or sputter deposition is based on condensation of the hot atoms onto a substrate which is kept at a temperature well below $T_{g}$. In this case the condensation process is presumably a vapor-solid transition. ${ }^{19}$ The condition for glass formation is that the condensed atoms are prevented from diffusing more than one atomic distance at the surface before they are fixed in position by the arrival of additional atoms. ${ }^{20}$ When using these techniques the glassy state may be stabilized by gas impurity atoms. ${ }^{19,22}$

The mechanism of glass formation by carbonyl decomposition in a liquid seems to be different from both of the methods discussed above. The chemical reactions which lead to the formation of the ferrofluid are quite complex. Previous studies of decomposition of iron ${ }^{6}$ and cobalt ${ }^{23}$ carbonyls in organic liquids indicate that interactions between carbonyl molecules and surfactant molecules take place. Moreover, during the growth of the particles catalytic decomposition of carbonyl molecules may take place at the surface of the particles. ${ }^{23}$

It is noteworthy that the molecules forming the metallic glass particles are at a temperature which does not exceed the boiling point of the liquid $(-460 \mathrm{~K})$. Thus the carbonyl-decomposition method, contrary to the two other methods discussed above, is not based on rapid cooling from a high temperature, but the mechanism is based on growth of alloy particles in a system which is kept at a temperature below $T_{g}$.

Since amorphous pure metals are not easily formed ${ }^{19,21}$ it is likely that the amorphous particles in the ferrofluid are stabilized by impurity atoms. The annealing experiment revealed the presence of about 11 at.\% carbon impurities in the amorphous particles. We therefore believe, in accordance with the proposal by Bjarmon and Wäppling, ${ }^{17}$ that these impurity atoms stabilize the amorphous phase. The latter investigations on sputtered iron showed that very small amounts of carbon, i.e., less than 6 at.\%, can stabilize the amorphous phase. It is likely that carbon atoms have entered the particles during the preparation of the ferrofluid as a result of chemisorption and disintegration of carbon monoxide on the surface of the particles. It is well known that iron metal catalysts are 
carburized by such a mechanism during FischerTropsch synthesis. ${ }^{24,25}$

In conclusion, we have found evidence for the formation of a metallic glass by thermal decomposition of $\mathrm{Fe}(\mathrm{CO})_{5}$, i.e., by a pure chemical reaction.

Financial support from the Danish Council for Scientific and Industrial Research is gratefully acknowledged.

1P. Duwez, Progress in Solid State Chemistry (Pergamon, Oxford, England, 1966), Vol. 3, p. 377.

${ }^{2}$ W. Buckel and R. Hilsch, Z. Phys. 138, 109 (1954).

${ }^{3}$ X. L. Yeh, K. Samwer, and W. L. Johnson, Appl. Phys. Lett. 42, 242 (1983).

${ }^{4}$ R. B. Schwarz and W. L. Johnson, Phys. Rev. Lett. 51, 415 (1983).

${ }^{5}$ C. H. Griffiths, M. P. O'Horo, and T. W. Smith, J. Appl. Phys. 50, 7108 (1979).

${ }^{6}$ T. W. Smith and D. Wychick, J. Phys. Chem. 84, 1621 (1980)

${ }^{7}$ S. W. Charles and J. Popplewell, in Ferromagnetic Materials, edited by E. P. Wohlfarth (North-Holland, Amsterdam, 1980), Vol. 2, p. 509.

${ }^{8}$ H. Winkler, J. Heinrich, and E. Gerdau, J. Phys. (Paris), Colloq. 37, C6-261 (1976).

${ }^{9}$ S. Mørup and H. Topsøe, Appl. Phys. 11, 63 (1976).

${ }^{10}$ S. Mørup, J. A. Dumesic, and H. Topsøe, in Applications of Mössbauer Spectroscopy, edited by R. L. Cohen (Academ- ic, New York, 1980), Vol. 2, p. 1.

11S. Mørup, J. Magn. Magn. Mater. 37, 39 (1983).

12B. S. Clausen, S. Mørup, and H. Topsøe, Surf. Sci. 106, 438 (1981).

${ }^{13}$ S. Mørup, H. Topsøe, and B. S. Clausen, Phys. Scr. 25, 713 (1982).

$14 \mathrm{~J}$. W. Niemantsverdriet, C. F. J. Flipse, A. M. van der Kraan, and J. J. van Loef, Appl. Surf. Sci. 10, 302 (1982).

${ }^{15}$ G. Le Caër, J. M. Dubois, M. Pijolat, V. Perrichon, and P. Bussiere, J. Phys. Chem. 86, 4799 (1982).

${ }^{16}$ C.-B. Ma, T. Ando, D. L. Williamson, and G. Krauss, Metall. Trans. A 14, 1033 (1983).

${ }^{17}$ S. Bjarman and R. Wäppling, J. Magn. Magn. Mater. 40, 219 (1983).

${ }^{18}$ H. Topsøe, B. S. Clausen, R. Candia, C. Wivel, and S. Mørup, J. Catal. 68, 433 (1981).

${ }^{19}$ M. G. Scott and R. Maddin, in Rapidly Quenched Metals, edited by N. J. Grant and B. C. Giessen (MIT Press, Cambridge, Mass., 1976), p. 249.

${ }^{20}$ F. E. Luborsky, in Ferromagnetic Materials, edited by E. P. Wohlfarth (North-Holland, Amsterdam, 1980), Vol. 1, p. 451 .

${ }^{21}$ H. A. Davies, in Amorphous Metallic Alloys, edited by F. E. Luborsky (Butterworth, London, 1983), p. 8.

${ }^{22}$ H. H. Liebermann, in Amorphous Metallic Alloys, edited by F. E. Luborsky (Butterworth, London, 1983), p. 26.

${ }^{23}$ E. Papirer, P. Horny, H. Balard, R. Anthore, C. Petipas, and A. Martinet, J. Colloid Interface Sci. 94, 220 (1983).

${ }^{24}$ J. A. Amelse, J. B. Butt, and L. H. Schwartz, J. Phys. Chem. 82, 558 (1978).

${ }^{25}$ G. B. Raupp and W. N. Delgass, J. Catal. 58, 348 (1979). 